\title{
Clinical Reasoning: A 47-year-old man with rapidly progressive ataxia and vitiligo
}

Fei Han, MD, Haitao Ren, MD, Mingyu Tang, MD, Yicheng Zhu, MD, and Hongzhi Guan, MD

Neurology ${ }^{\circledR}$ 2020;94:e1664-1669. doi:10.1212/WNL.0000000000009242

Correspondence

Dr. Guan

pumchghz@126.com

\section{Section 1}

A 47-year-old man, with a medical history of vitiligo, presented to Peking Union Medical College Hospital for evaluation of progressive gait instability over a period of 10 months. $\mathrm{He}$ was initially noticed to walk with drunken gait and have difficulty performing accurate movements during goal-directed tasks. The patient also complained of difficulty in speaking and reported that objects appeared to move back and forth across his field of vision. The symptoms worsened, and he could not walk without assistance in the recent 2 months. There was no preceding infection or known family history of ataxia. The patient denied alcoholism.

General clinical examination showed extensive vitiligo (figure, A). On neurologic examination, mental status was normal. The patient had slow, slurred, and irregular speech.

Figure Vitiligo distribution and brain MRI

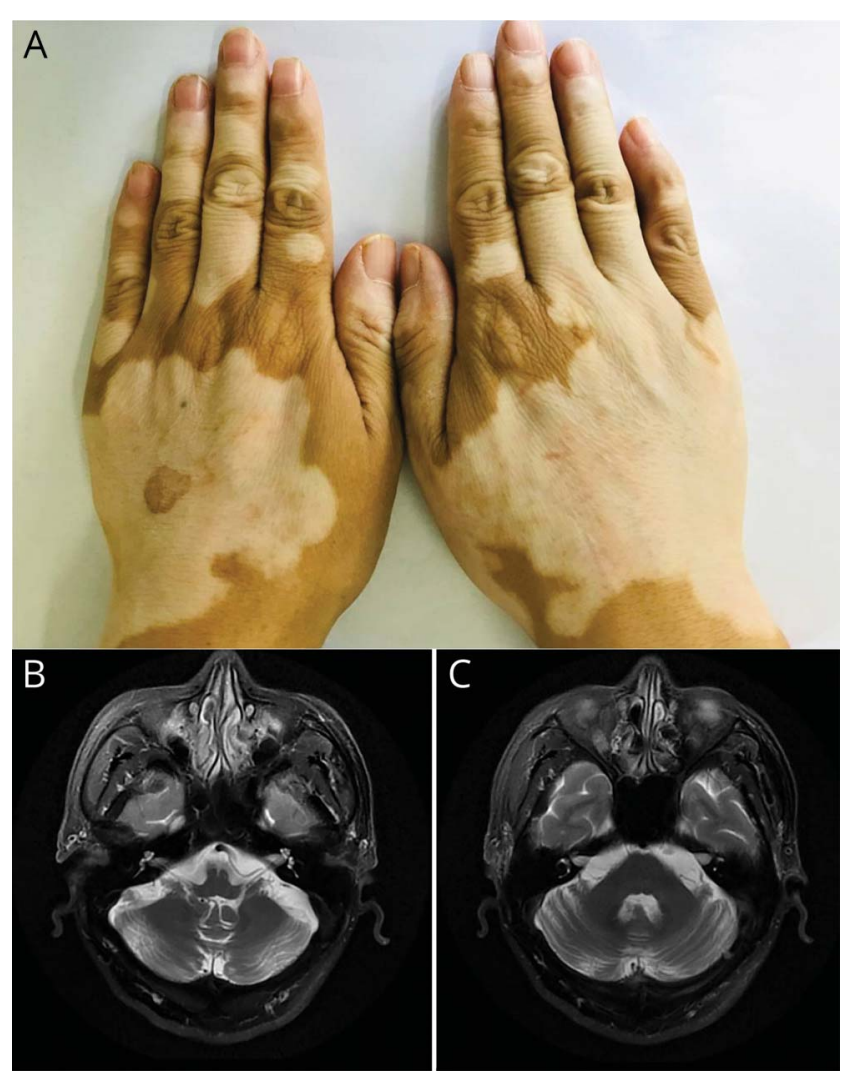

(A) The patient's hands with vitiligo. (B, C) Axial T2-wighted MRI sequence shows cerebellar atrophy.

From the Department of Neurology, Peking Union Medical College Hospital, Chinese Academy of Medical Science, Beijing, China.

Go to Neurology.org/N for full disclosures. Funding information and disclosures deemed relevant by the authors, if any, are provided at the end of the article. 
Cranial nerve examination was significant for broken smooth pursuits and rotatory nystagmus with leftward fast component. Strength and tendon reflexes were normal throughout, with flexor plantar responses. The examinations of coordinate movements revealed bilateral dysmetria on finger-to-nose and heel-to-shin testing, intention tremor, and dysdiadochokinesia with rapid alternating movements. Sensory examinations were normal. Gait imbalance was prominent, and the patient tended to fall when standing with his feet together whether his eyes were opened or closed.

\section{Questions for consideration:}

1. What is the localization for the patient's presentation?

2. What are the differential diagnoses and what further tests can be performed for evaluation? 


\section{Section 2}

Based on the clinical presentations and physical signs of truncal and limb ataxia, accompanied by gaze-evoked nystagmus, and dysarthria due to oral motor ataxia, cerebellar hemispheres and midline cerebellar structures were involved.

When approaching a patient with cerebellar ataxia, the first major point in the clinical decision tree is the onset and duration of the symptom. Although no formal definition exists, subacute cerebellar ataxia is generally defined as ataxia that occurs in days to weeks, with progression occurring over weeks to months rather than years, while chronic ataxia usually develops in months to years. Etiologies of subacute ataxia include (1) atypical infections, including progressive multifocal leukoencephalopathy; (2) metabolic factors, including systemic metabolic disorders, chronic exposure to toxins or medications, alcohol abuse, and vitamin deficiencies; (3) autoimmune etiologies, including CNS demyelinating disease, systemic immune disorders, autoantibody mediated ataxia, and paraneoplastic cerebellar degeneration; and (4) neoplasms, including primary or metastatic tumors involving the cerebellum. An initial workup usually includes basic laboratory data and extensive laboratory testing to identify infectious and inflammatory etiologies. Malignancy screening is necessary in patients with subacute progression combined with weight loss and cachexia. Brain MRI is recommended for the evaluation of space-occupying and demyelinating lesions.
In this case, routine blood tests including complete blood count, erythrocyte sedimentation rate, fasting glucose, liver function, renal profile, HIV, and syphilis serologies were unremarkable. Common metabolic causes of ataxia were ruled out as the levels of vitamin $B_{12}$, folate, vitamin $E$, copper, and thyroid-stimulating hormone were normal. Lack of antinuclear antibodies and antineutrophil cytoplasmic antibodies lowered the likelihood of systemic autoimmune diseases. CNS demyelinating diseases and neoplasms were excluded as the brain MRI showed mild cerebellar atrophy with no other abnormalities (figure, B and C). The CSF analysis revealed no evidence of infectious etiologies, with normal white cell count and protein and glucose levels and negative cultures. Owing to the rapidly progressive course, autoimmune ataxia was highly suspected. Serum and CSF samples were tested for autoantibodies including anti-glutamate decarboxylase 65 (GAD65) antibody, anti-Yo (Purkinje cell antibody 1) antibody, and anti-Tr (delta/ notch-like epidermal growth factor-related receptor [DNER]) antibodies by using a commercial cell-based assay (FA 112d1003-1; EUROIMMUN AG, Lübeck, Germany). Anti-Tr antibodies were positive in the serum and CSF, and their titers were both 1:32. An extensive workup for malignancy was negative, including thoracic, abdominal, and pelvic contrasted CT and whole body PET CT scan.

\section{Question for consideration:}

1. What is the final diagnosis and what treatments can be performed?

GO TO SECTION 3 


\section{Section 3}

Based on the patient's history of progressive cerebellar ataxia and positive anti- $\operatorname{Tr}$ antibody status, autoimmune cerebellar ataxia (ACA) was diagnosed. The patient was started on IV immunoglobulin (IVIg) $2 \mathrm{~g} / \mathrm{kg}$ divided over 5 days followed by oral prednisone $(60 \mathrm{mg} /$ day). Following initial treatment, the patient's gait instability and dysmetria were improved. He was started on mycophenolate mofetil $750 \mathrm{mg}$ twice daily and prednisone was tapered gradually.
At 3 months follow-up, he was able to walk slowly without assistance, with a drop of 1 point in modified Rankin Scale score (from 4 to 3 ). He continues to have mild gait ataxia. Repetition of cancer screening was recommended for the patient 6 months after the initial evaluation. The clinical and radiologic long-term outcomes will be followed up closely.

Question for consideration:

1. What is the diagnostic value of vitiligo in this case?

GO TO SECTION 4 


\section{Section 4}

The medical history and physical sign of vitiligo were noted in this patient. Vitiligo was thought to be an acquired organspecific autoimmune disorder that targets melanocytes, characterized by progressive skin depigmentation, with absence of melanocytes microscopically. Most evidence supports immune-mediated melanocyte damage as the main etiologic pathway in the pathogenesis. Vitiligo could coexist with other autoimmune disorders, which reflects a systemic process that has important implications beyond the skin. ${ }^{1}$

An innovative concept based on a functional cross-link between the nervous and immune system in the pathogenesis of vitiligo is emerging. Vitiligo has been reported to be present in patients with neuroimmune disorders, involving both peripheral nervous system and CNS. A crosssectional study of 1,098 patients with vitiligo reported several comorbid autoimmune neurologic diseases, including 3 Guillain-Barré syndrome (0.2\%), 2 myasthenia gravis $(0.2 \%)$, and 2 multiple sclerosis $(0.2 \%) .{ }^{1}$ A Mayo Clinic cohort study showed that in a series of 62 patients with GAD65 antibody-positive ACA, 10 (16\%) had vitiligo. ${ }^{2}$ Guan $^{3}$ reported 3 patients with autoimmune encephalitis accompanied by vitiligo. Among them, 2 had anti-leucine-rich glioma-inactivated 1 encephalitis and 1 had anti-IgLON5 encephalopathy; both antigens were plasma membrane proteins (PMPs).

Although the nature of the association between neuroimmune disease and vitiligo is not completely understood, underlying mechanisms have been proposed. Both the skin and the nervous system are derived from the external germ layer, which provide the theoretical basis for the hypothesis that the autoantibodies induced by the exposure antigen triggered by vitiligo are more likely to attack the mimic extracellular epitopes of neuronal cell surface. The link between anti-Tr ACA and vitiligo has not been reported previously. Our case extends the spectrum of autoimmune association between vitiligo and neuroimmune disorders. Coexistence of vitiligo might be a diagnostic clue to an autoimmune cause for cerebellar ataxia. This hypothesis should be demonstrated further by investigating the exposure antigens expressed by both melanocytes and neural cells.

\section{Discussion}

ACA represents an important differential diagnosis in patients presenting with rapidly progressive cerebellar disease. ${ }^{4}$ ACAs are more frequently recognized due to advances in detecting autoantibodies. The anti-Tr antibody was first described in 1976 by Trotter et al. ${ }^{5}$ in a female patient with subacute paraneoplastic cerebellar degeneration and Hodgkin disease. DNER, the target antigen of anti- $\mathrm{Tr}$, is a single- pass type I transmembrane protein highly expressed in Purkinje cell bodies and dendrites, as well as in various types of CNS neurons. ${ }^{6}$ ACA with anti-Tr antibody is rare and associated neurologic manifestations include subacute and severe cerebellar ataxia, encephalopathy, and sensory neuropathy. A large cohort study conducted at Mayo Clinic showed that anti-Tr antibody was detected in only 1 of the 118 neuronal autoantibody-seropositive patients with ataxia. ${ }^{4}$ Anti-Tr/DNER antibodies are almost exclusively found in patients with Hodgkin disease. Only a few patients have been reported in whom no Hodgkin disease (or any other tumor) was known at the time of testing. ${ }^{7}$ We present a patient with tumor-negative progressive cerebellar ataxia, which is a rare condition in anti-Tr antibody-positive ACA. We speculate that vitiligo may be a diagnostic clue to an autoimmune etiology for this case.

Although autoimmune ataxia is usually severe, responsiveness to immunotherapy can be gratifying, particularly in patients with nonparaneoplastic disorders and in those with autoantibodies directed against neural PMPs. In the Mayo Clinic series of 118 patients with ACA, nearly half had neurologic improvement with immunotherapy, which was robust in $18.6 \% .{ }^{4}$ Clinical recognition of autoimmune etiology and timely immunotherapy are critical for favorable functional outcome. For these patients, initiating high-dose corticosteroids or IVIg (or both sequentially) is indicated, and maintenance immunosuppressive therapy is required for sustained responses. Although the duration of therapy is uncertain, general recommendations are available. ${ }^{8}$ Evaluation for and treatment of any underlying cancer is another component for those patients with a paraneoplastic cause.

\section{Study funding}

No targeted funding reported.

\section{Disclosure}

The authors report no relevant disclosures. Go to Neurology. org/ $\mathrm{N}$ for full disclosures.

\begin{tabular}{|c|c|c|}
\hline Name & Location & Contribution \\
\hline $\begin{array}{l}\text { Fei Han, } \\
\text { MD }\end{array}$ & $\begin{array}{l}\text { PUMCH, } \\
\text { Beijing, China }\end{array}$ & Analyzed the data, drafted the manuscript \\
\hline $\begin{array}{l}\text { Haitao } \\
\text { Ren, MD }\end{array}$ & $\begin{array}{l}\text { PUMCH, } \\
\text { Beijing, China }\end{array}$ & Analyzed the data \\
\hline $\begin{array}{l}\text { Mingyu } \\
\text { Tang, MD }\end{array}$ & $\begin{array}{l}\text { PUMCH, } \\
\text { Beijing, China }\end{array}$ & Acquisition of data, analyzed the data \\
\hline $\begin{array}{l}\text { Yicheng } \\
\text { Zhu, MD }\end{array}$ & $\begin{array}{l}\text { PUMCH, } \\
\text { Beijing, China }\end{array}$ & Interpretation of data \\
\hline $\begin{array}{l}\text { Hongzhi } \\
\text { Guan, MD }\end{array}$ & $\begin{array}{l}\text { PUMCH, } \\
\text { Beijing, China }\end{array}$ & $\begin{array}{l}\text { Acquisition of data, interpretation of data, } \\
\text { revised the manuscript for intellectual } \\
\text { content }\end{array}$ \\
\hline
\end{tabular}




\section{References}

1. Gill L, Zarbo A, Isedeh P, et al. Comorbid autoimmune diseases in patients with vitiligo: a cross-sectional study. J Am Acad Dermatol 2016;74:295-302.

2. Pittock SJ, Yoshikawa H, Ahlskog JE, et al. Glutamic acid decarboxylase autoimmunity with brainstem, extrapyramidal, and spinal cord dysfunction. Mayo Clin Proc 2006;81:1207-1214

3. Haitao R, Huiqin $\mathrm{L}, \mathrm{Tao} \mathrm{Q}$, et al. Autoimmune encephalitis associated with vitiligo? J Neuroimmunol 2017;310:14-16.

4. Jones AL, Flanagan EP, Pittock SJ, et al. Responses to and outcomes of treatment of autoimmune cerebellar ataxia in adults. JAMA Neurol 2015;72:1304-1312.
5. Trotter JL, Hendin BA, Osterland CK. Cerebellar degeneration with Hodgkin disease: an immunological study. Arch Neurol 1976;33:660-661.

6. de Graaff E, Maat P, Hulsenboom E, et al. Identification of delta/notch-like epidermal growth factor-related receptor as the $\operatorname{Tr}$ antigen in paraneoplastic cerebellar degeneration. Ann Neurol 2012;71:815-824.

7. Bernal F, Shams'ili S, Rojas I, et al. Anti-Tr antibodies as markers of paraneoplastic cerebellar degeneration and Hodgkin's disease. Neurology 2003;60:230-234.

8. McKeon A. Immunotherapeutics for autoimmune encephalopathies and dementias. Curr Treat Options Neurol 2013;15:723-737. 


\section{Neurology}

\section{Clinical Reasoning: A 47-year-old man with rapidly progressive ataxia and vitiligo}

Fei Han, Haitao Ren, Mingyu Tang, et al.

Neurology 2020;94;e1664-e1669 Published Online before print March 12, 2020

DOI 10.1212/WNL.0000000000009242

This information is current as of March 12, 2020

Updated Information \&

Services

References

Subspecialty Collections

Permissions \& Licensing

Reprints including high resolution figures, can be found at: http://n.neurology.org/content/94/15/e1664.full

This article cites 8 articles, 1 of which you can access for free at: http://n.neurology.org/content/94/15/e1664.full\#ref-list-1

This article, along with others on similar topics, appears in the following collection(s):

Autoimmune diseases

http://n.neurology.org/cgi/collection/autoimmune_diseases Other Education

http://n.neurology.org/cgi/collection/other_education

Information about reproducing this article in parts (figures,tables) or in its entirety can be found online at:

http://www.neurology.org/about/about_the_journal\#permissions

Information about ordering reprints can be found online:

http://n.neurology.org/subscribers/advertise

Neurology ${ }^{\circledR}$ is the official journal of the American Academy of Neurology. Published continuously since 1951, it is now a weekly with 48 issues per year. Copyright @ 2020 American Academy of Neurology. All rights reserved. Print ISSN: 0028-3878. Online ISSN: 1526-632X.

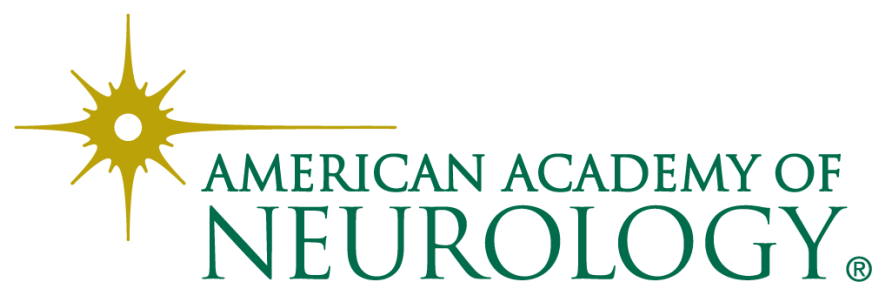

